\title{
Determination of uranium concentrations and its activity ratios in coal and fly ash from Philippine coal-fired thermal power plants using ICP-MS and TIMS
}

\author{
By S. K. Sahoo ${ }^{1, *}$, V. K. Parami ${ }^{2}$, L. L. Quirit ${ }^{3}$, H. Yonehara ${ }^{1}$, T. Ishikawa ${ }^{1}$ and S. Tokonami ${ }^{1}$ \\ ${ }_{1}^{1}$ Research Centre for Radiation Protection, National Institute of Radiological Sciences, 4-9-1 Anagawa, Inage, Chiba 263-8555, Japan \\ 2 Philippine Nuclear Research Institute, Diliman, Quezon City 1101, Philippines \\ ${ }^{3}$ Institute of Chemistry, University of the Philippines, Diliman, Quezon City 1101, Philippines
}

(Received December 1, 2009; accepted in revised form November 12, 2010)

\section{TENORM / Uranium / Activity ratio / \\ Gamma spectroscopy / ICP-MS / TIMS}

\begin{abstract}
Summary. The specific activity of ${ }^{238} \mathrm{U}$ as a technologically enhanced naturally occurring radioactive material (TENORM) in feed coal, bottom and fly ash samples from four major coal-fired thermal power plants in the Philippines have been measured using high-resolution gamma-ray spectroscopy system equipped with a high-purity germanium (HPGe) detector. The uranium concentration has been determined from same samples using inductively coupled plasma mass spectrometry (ICP-MS). There was a good correlation between the measured uranium using both methods and has been estimated to be 0.98 . Uranium from coal, bottom and fly ash samples were chemically separated and activity ratio $\left({ }^{234} \mathrm{U} /{ }^{238} \mathrm{U}\right)$ and ${ }^{235} \mathrm{U} /{ }^{238} \mathrm{U}$ ratio was measured using a thermal ionization mass spectrometer (TIMS). The highest concentration of uranium was found in fly ash and lowest was for feed coal. Uranium isotopic composition plays an important role in studying its biogeochemical behavior and is a good tracer on the sources of uranium in the environment.
\end{abstract}

\section{Introduction}

Increased interest in measuring naturally occurring radionuclide concentrations in coal and fly ash is due to the awareness of health hazards and of these materials contributing to environmental pollution [1]. The worldwide production of coal ash is approaching $1 \mathrm{Gt}$ annually and the amount of ash containing NORM and other mobile toxic elements that has to be dealt with is continuously increasing. Combustion by-products of coal-fired power plants are distributed in the environment as atmospheric discharges. Bottom and fly ash is disposed in landfill or settling ponds and sea, they are also used for the manufacture of building, road and dam construction materials. These contain long-lived radionuclides such as ${ }^{238} \mathrm{U}$ and ${ }^{232} \mathrm{Th}$. In the Philippines, the determination of TENORM levels in fly ash becomes imperative as the country has more than ten coal-fired thermal power plants currently in operation and more plants are to be constructed in the future.

\footnotetext{
*Author for correspondence (E-mail: sahoo@ nirs.go.jp).
}

Uranium is one of the heaviest naturally occurring radioactive elements. Depending on the geological condition, its worldwide median concentration in soil is $35 \mathrm{~Bq} / \mathrm{kg}$ or $2.8 \mathrm{mg} / \mathrm{kg}$ [2]. Its radiotoxicity and chemical toxicity have been well documented [3]. Uranium comprises three natural occurring isotopes e.g. ${ }^{234} \mathrm{U},{ }^{235} \mathrm{U}$ and ${ }^{238} \mathrm{U}$ with the isotopic abundances being approximately of $0.0055 \%, 0.7200 \%$ and $99.2745 \%$, respectively [4]. The principal isotopes of primordial origin are ${ }^{238} \mathrm{U}$ and ${ }^{235} \mathrm{U}$, with ${ }^{234} \mathrm{U}$ present approximately in radioactive equilibrium with ${ }^{238} \mathrm{U}[5],{ }^{236} \mathrm{U}$ occurs in nature at ultra trace concentrations. ${ }^{235} \mathrm{U}$ and ${ }^{238} \mathrm{U}$ ratios may have small variations depending on the geographic origin of the sample, due to natural isotopic fractionation, nuclear reactions or anthropogenic contamination. Under normal circumstances, enriched ${ }^{235} \mathrm{U}$ indicates a source of nuclear weapon test or nuclear reactor accidents whereas depleted ${ }^{235} \mathrm{U}$ is a result of uranium enrichment in the manufacture of enriched uranium used as a fuel in nuclear reactors and nuclear weapons $[6,7]$. Another source of radioactivity in the environment is the release of technologically enhanced naturally occurring radioactive material (TENORM) by coal, fly ash, oil, natural gas, mineral, ore refining, production of phosphate fertilizers and disposal of uranium mill tailings. As opposed to above mentioned instances there is no change in the isotopic composition of ${ }^{235} \mathrm{U} /{ }^{238} \mathrm{U}$. However, ${ }^{234} \mathrm{U} /{ }^{238} \mathrm{U}$ isotopic composition (activity ratio) variation has been noticed in water, soil, sediment and uranium ore sample [8-10]. Therefore, uranium isotopic composition plays an important role in studying its biogeochemical behavior and is a good tracer on the source of uranium in the environment.

Although $\alpha$-spectrometry is the common choice for the measurement of activity ratios, in recent days, mass spectrometry using inductively coupled plasma as an ion source (ICP-MS) is now accepted as a versatile analytical technique for elemental and isotopic analysis [11-13]. Thermal ionization mass spectrometry (TIMS) has been accepted as a "benchmark" technique for isotopic analysis $[14,15]$. Recently, high precision uranium isotopic measurements are in rapid process using multi-collector inductively coupled plasma mass spectrometry (MC-ICP-MS) $[9,16,17]$ and thermal ionisation mass spectrometry (TIMS) equipped with energy filters $[18,19]$. 
Extraction chromatography with UTEVA resin has been utilized for the preconcentration and separation of $\mathrm{U}$ [20, 21].

The concentration of uranium in coal, bottom and fly ash samples from Philippine coal-fired thermal power plants has been determined using ICP-MS whereas ${ }^{234} \mathrm{U} /{ }^{238} \mathrm{U}$ activity ratio and ${ }^{235} \mathrm{U} /{ }^{238} \mathrm{U}$ ratio have been measured using thermal ionization mass spectrometry. The resulting data can be used as bases for regulatory control, radiological impact assessment, and classification of coal ash for construction purposes.

\section{Experimental procedure}

\subsection{Study area}

The coal-fired thermal power plants A, B, C and D where feed coal and ash samples were obtained are all located in Luzon Island, Philippine. Plants A and B are located in the southern part of Luzon whereas C and D plants are located in northern part of Luzon (Fig. 1). Each plant's operating capacity, start of operation, origin of coal used during the sampling period, size of ash ponds, and height of stacks are given in Table 1.

\subsection{Sample collection and preparation}

About $2-3 \mathrm{~kg}$ of feed coal (FC), bottom ash (BA) and fly ash (FA) samples were collected from four Philippine thermal

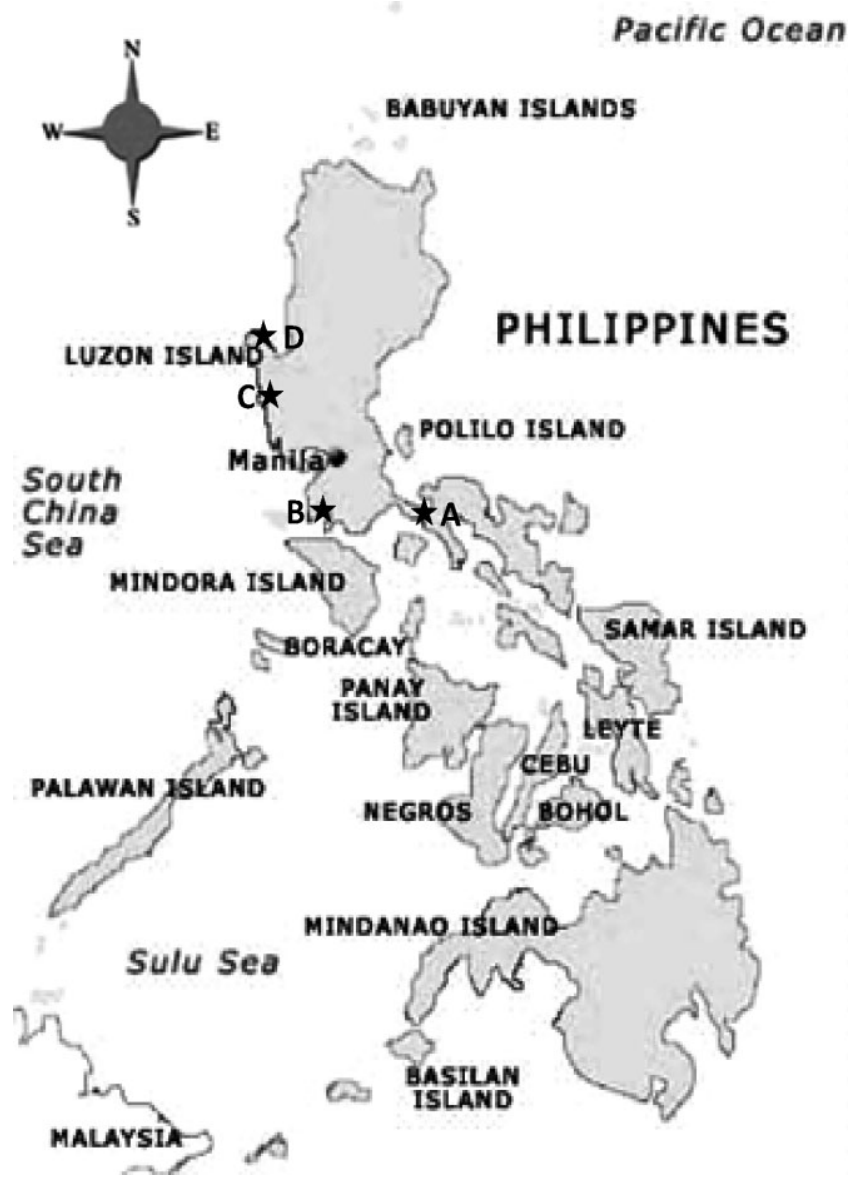

Fig. 1. Map showing sampling stations in Luzon island.
Table 1. Description of four Philippines coal-fired thermal plants.

\begin{tabular}{lccccc}
\hline $\begin{array}{c}\text { Plant } \\
\text { name }\end{array}$ & $\begin{array}{c}\text { Production } \\
(\mathrm{MW})\end{array}$ & $\begin{array}{c}\text { Starting } \\
\text { year }\end{array}$ & $\begin{array}{c}\text { Coal } \\
\text { origin }\end{array}$ & $\begin{array}{c}\text { Ash pond } \\
\text { area }\left(\mathrm{m}^{2}\right)\end{array}$ & $\begin{array}{c}\text { Stack } \\
\text { height }(\mathrm{m})\end{array}$ \\
\hline A-1 & 300.00 & 1984 & Indonesia & & 120 \\
A-2 & 350.00 & 1995 & & 640000 & 150 \\
B-1 & 367.50 & 1996 & Indonesia & & 220 \\
B-2 & 367.50 & 1996 & & 222570 & \\
C-1 & 300.00 & 1998 & China & & 150 \\
C-2 & 350.00 & 1998 & & 816800 & \\
D-1 & 609.00 & 1999 & China & & 240 \\
D-2 & 609.00 & 1999 & & 1400000 & \\
\hline
\end{tabular}

power plants. The FA samples from plant B were collected from the $1^{\text {st }}$ and $2^{\text {nd }}$ stages (near to the stack) of the electro static precipitator (ESP) whereas the FA sampling points of the other plants ESP stages were not indicated. All samples were oven dried at $80^{\circ} \mathrm{C}$ until weight was constant, pulverized using a mortar and pestle (except for the fly ash samples), and homogenized using a $500 \mu \mathrm{m}$ mesh size sieve.

\subsection{Instruments}

A high-purity germanium detector (ORTEC GEM-100210) $\gamma$-spectroscopy coupled with a multi-channel analyzer (ORTEC-7700-010) and gamma studio software (Seiko EG\&G, 2000) was used for the measurement of specific activity of radionuclides.

A Hewlett Packard ICP-MS HP-4500 (Yokogawa Analytical Instruments, Tokyo, Japan) was used for the measurement of $U$ which yielded detection limits of $0.01-$ $0.003 \mu \mathrm{g} / \mathrm{L}(0.12-0.037 \mathrm{mBq} / \mathrm{kg})$. The ICP-MS detection limit was calculated as three times the standard deviation of the calibration blank measurements $\left(1: 1 \mathrm{v} / \mathrm{v} \mathrm{HNO}_{3}\right.$ : Milli $\mathrm{Q}$ water, $n=10$ ). The relative error of ICP-MS results for the reference sample (lake sediment JLK-1) for ${ }^{238} \mathrm{U}$ was $0.56 \%$. The parameters for data acquisition and optimization conditions are reported elsewhere [22].

A VG Sector 54-30 thermal ionization mass spectrometer (VG Isotopes Ltd., UK), equipped with nine Faraday cup collectors and Daly ion detection system positioned behind axial Faraday and wide aperture retardation potential (WARP) energy filter, was used for the isotopic measurement of uranium.

\subsection{Reagents and standards}

High purity water was obtained with a Millipore Milli-Q water purification system. High purity $\mathrm{HCl}, \mathrm{HNO}_{3}, \mathrm{HF}$ and $\mathrm{HClO}_{4}$ were purchased from Tamapure chemical industries (Kawasaki, Japan). The strong anion exchange resin Dowex 1X-8 (200-400 mesh, $\mathrm{Cl}^{-}$form) was purchased from BioRad Labs (Richmond, CA). It was soaked in $6 \mathrm{M} \mathrm{HNO}_{3}$ and subsequently washed with distilled water. Commercial extraction chromatographic resin, UTEVA was purchased from Eichrom Industries (Darien, IL) and was conditioned with $8 \mathrm{M} \mathrm{HNO}_{3}$.

\subsection{Chemical procedures}

Feed coal (FC), bottom ash (BA) and fly ash (FA) samples were digested with $\mathrm{HNO}_{3}, \mathrm{HF}$ and $\mathrm{HClO}_{4}$ in PTFE pressure 
decomposition vessels. A microwave unit (MLS 1200 mega, Italy) was used for heating the sample. The samples were evaporated to dryness on a hot plate after digestion. Finally, the residues were dissolved in $8 \mathrm{M} \mathrm{HNO}_{3}$ to yield the sample solution for chemical separation.

We have used a combination of anion exchange and extraction chromatography with a little modification of earlier methods [20,21]. First column was prepared using precleaned anion exchange resins (Dowex 1X-8, 200-400 mesh, $\mathrm{Cl}^{-}$form) and packed into $2 \mathrm{~cm}$ internal diameter Pyrex columns up to a height of $6 \mathrm{~cm}$ and the second $1.0 \times 0.5 \mathrm{~cm}$ internal diameter column containing Eichrom UTEVA resin. Both columns were conditioned by passing $15 \mathrm{ml}$ of $8 \mathrm{M}$ $\mathrm{HNO}_{3}$. The sample was transferred to anion exchange column and the eluent was subsequently passed onto the UTEVA column. Both columns were washed with $10 \mathrm{ml}$ of $8 \mathrm{M} \mathrm{HNO}_{3}$ followed by $20 \mathrm{ml}$ of $3 \mathrm{M} \mathrm{HNO}_{3}$. U was eluted from UTEVA column using $5 \mathrm{ml}$ of $0.02 \mathrm{M} \mathrm{HCl}$. Concentration of eluent was adjusted to $9 \mathrm{M} \mathrm{HCl}$. The resulting solution was loaded onto an anion exchange column preconditioned with $9 \mathrm{M} \mathrm{HCl}$ and washed with $10 \mathrm{ml}$ of $9 \mathrm{M} \mathrm{HCl}$. Finally, $\mathrm{U}$ was eluted with $10 \mathrm{ml}$ of $0.02 \mathrm{M} \mathrm{HCl}$ and the eluent was evaporated to dryness in a Teflon beaker. Recovery of $U$ from the samples were about $80 \sim 90 \%$.

\subsection{Gamma spectroscopy}

About $100 \mathrm{~g}$ of split homogenized dried samples were stored in airtight U-8 standard cylindrical containers (diameter $=$ $48 \mathrm{~mm}$; height $=58 \mathrm{~mm}$ ) for $30 \mathrm{~d}$ to attain secular equilibrium of ${ }^{226} \mathrm{Ra}$ and its progeny. The detector efficiency was determined using a $100 \mathrm{~g}$ multi-nuclide standard source supplied by Japan Radioisotope Association with quoted gamma energies ranging from 60 to $1333 \mathrm{keV}$ an overall uncertainty of less than 5\%. The activity concentration of ${ }^{226} \mathrm{Ra}$ was measured using the HPGe $\gamma$-spectrometer described above. Details of this technique have been given elsewhere [23]. The results were compared with a natural soil standard IAEA-375 (International Atomic Energy Agency, natural soil standard) to check the reproducibility of method. The ${ }^{226} \mathrm{Ra}$ concentrations were determined by measuring the activities of its decay products ${ }^{214} \mathrm{~Pb}$ (295 and $352 \mathrm{keV})$ and ${ }^{214} \mathrm{Bi}(609$ and $1120 \mathrm{keV})$.

\subsection{Mass spectrometry}

A triple filament assembly was used for the thermal ionization of uranium isotopes. The filament material was 5 pass zone refined rhenium ribbon (H. Cross, 99.999\%) with $0.003 \mathrm{~cm}$ thickness and $0.07 \mathrm{~cm}$ width. The isolated $\mathrm{U}$ fraction was loaded onto a separable outer filament and heated with a 0.9 A current to leave a dry residue. Mass spectrometry analytical scheme in detail has been described elsewhere [15].

\section{Results and discussion}

The results of three replicate analyses of the uranium concentrations $\left(\mathrm{Bq} \mathrm{kg}^{-1}\right)$ in $\mathrm{FC}, \mathrm{BA}$ and FA samples from the four coal-fired thermal power plants were measured by $\gamma$ spectroscopy and ICP-MS are summarized in Table 2. The
Table 2. Comparison between $\gamma$-spectroscopy and ICP-MS methods for the measurement of uranium concentration $\left(\mathrm{Bq} \mathrm{kg}^{-1}\right)$.

\begin{tabular}{lccc}
\hline Sample & Plant & $\begin{array}{c}\gamma \text {-spectroscopy } \\
{ }_{226} \mathrm{Ra}\end{array}$ & \multicolumn{1}{c}{ ICP-MS } \\
& & & \\
\hline FC & $\mathrm{A}$ & $11.7 \pm 1.4$ & $2.6 \pm 0.1$ \\
$\mathrm{BA}$ & $\mathrm{A}$ & $29.9 \pm 2.2$ & $30.2 \pm 1.2$ \\
ESP $1^{\text {st }}$ & $\mathrm{A}$ & $53.4 \pm 3.4$ & $59.8 \pm 2.4$ \\
ESP 2 & $\mathrm{A}$ & $56.3 \pm 3.6$ & $69.9 \pm 4.2$ \\
FC & $\mathrm{B}$ & $1.8 \pm 1.3$ & $2.9 \pm 0.1$ \\
BA & $\mathrm{B}$ & $51.6 \pm 3.6$ & $57.9 \pm 3.5$ \\
FA & $\mathrm{B}$ & $50.8 \pm 3.4$ & $268.0 \pm 10.7$ \\
FC & $\mathrm{C}$ & $6.7 \pm 1.2$ & $5.8 \pm 0.1$ \\
BA & $\mathrm{C}$ & $106.7 \pm 6.7$ & $55.6 \pm 1.7$ \\
FA & $\mathrm{C}$ & $109.6 \pm 6.8$ & $83.2 \pm 2.1$ \\
FC & $\mathrm{D}$ & $10.1 \pm 1.5$ & $13.7 \pm 0.8$ \\
BA & $\mathrm{D}$ & $83.3 \pm 5.3$ & $100.2 \pm 4.1$ \\
FA & $\mathrm{D}$ & $131.13 \pm 8.1$ & $132.4 \pm 10.6$ \\
\hline
\end{tabular}

highest activity concentration of ${ }^{226} \mathrm{Ra}$ was observed in FC samples of plant A while for plant B was the lowest in FC irrespective of same origin i.e. from Indonesia. In case of BA samples, Plant $\mathrm{C}$ had the highest concentration of ${ }^{226} \mathrm{Ra}$. Plant D had the highest concentration of ${ }^{226} \mathrm{Ra}$ in FA samples. Concentrations of ${ }^{238} \mathrm{U}$ were found to be high in China FC samples operated in plants $\mathrm{C}$ and $\mathrm{D}$ in comparison to Indonesia FC used in plants A and B. There were different trends for BA and FA samples. Plant D had the highest ${ }^{238} \mathrm{U}$ concentration whereas plant $\mathrm{B}$ had the highest activity concentration of ${ }^{238} \mathrm{U}$ in FA sample. The concentration of ${ }^{238} \mathrm{U}$ was comparable in BA and FA samples from plants A and C.

The correlation of ${ }^{226} \mathrm{Ra}$ with ${ }^{238} \mathrm{U}$ for samples analyzed using ICP-MS and HPGe $\gamma$-spectroscopy is shown in Fig. 2. A good correlation $\left(R^{2}=0.98\right)$ was obtained between the two analytical techniques excluding three aberrant data points. The slopes for the HPGe $\gamma$-spectroscopy $v s$. ICP-MS data had values near unity (around 0.90) and intercept near zero which indicates an approximate one to one correspondence between the two techniques. The data points for FA sample (Plant B) were more aberrant in the correlation plots in comparison with FA and BA samples (Plant C) to a lesser degree in the ${ }^{238} \mathrm{U}$ series. Plant C's BA and FA samples have higher concentration of ${ }^{226} \mathrm{Ra}$ than ${ }^{238} \mathrm{U}$. The degree of partitioning of the radionuclide between bottom ash and fly ash during the combustion process is influenced by the condition of plants furnace and the physical and chemical form of the



Fig. 2. Correlation between the ICP-MS and $\gamma$-spectroscopy measurement. 
Table 3. Measurement of ${ }^{234} \mathrm{U} /{ }^{238} \mathrm{U}$ isotope ratio and activity ratio.

\begin{tabular}{lcc}
\hline Sample & ${ }^{234} \mathrm{U} /{ }^{238} \mathrm{U}$ & Activity ratio \\
\hline Zircon (Sulinjarvi) & 0.0000547 & 0.9998 \\
Zircon (Perak) & 0.00005469 & 0.9997 \\
\hline
\end{tabular}

For activity ratio calculation, $\lambda_{238}=1.551 \times 10^{-10}$ and $\lambda_{234}=2.835 \times$ $10^{-6}$ has been used [9].

feed coal. The results indicate that the HPGe $\gamma$-spectroscopy analytical technique can generally be used for activity concentration determination of radionuclides. However, this is an indirect method and is based on the assumption that secular equilibrium exists between ${ }^{238} \mathrm{U}$ and its decay products. In order to accurately measure TENORM concentrations, various available techniques have to be utilized depending on the physical and chemical form of radionuclide of interest. Since ICP-MS method measures mass concentrations, it is more accurate.

In coal samples, secular equilibrium exists between ${ }^{238} \mathrm{U}$ and its decay products, especially when the coal is undisturbed for very long period of time. But this may not be true for relatively "young coal" e.g., lignites and sub-bituminous. Definitely, secular equilibrium may not exist in combusted coal or in ashes. Therefore, activity ratio measurement may be helpful to understand its origin if there is a large variation in the concentration.

To check accuracy of the isotopic composition of uranium by TIMS method, NBS standards, NBS U010 with known isotopic compositions were analysed. The isotope ratio, ${ }^{235} \mathrm{U} /{ }^{238} \mathrm{U}$ was corrected for non-linearity of Daly-ion detector by $0.15 \%$ per $10^{-13} \mathrm{~A}$. The results of ${ }^{234} \mathrm{U} /{ }^{238} \mathrm{U}$ and ${ }^{235} \mathrm{U} /{ }^{238} \mathrm{U}$ isotope ratios were $0.0000546 \pm 0.0000002$ and $0.0101424 \pm 0.000005$ against certified value of 0.0000546 and 0.010140 respectively. Thus, the measurements of the isotopic ratio in the standards demonstrate that isotopic fractionation, if occurring in the system, is less than the uncertainty in the measurement. A precision of better than $0.20 \%$ at the $95 \%$ uncertainty level $(n=60)$ on ${ }^{235} \mathrm{U} /{ }^{238} \mathrm{U}$ has been obtained. Zircon samples were analysed for comparison of ${ }^{234} \mathrm{U} /{ }^{238} \mathrm{U}$ isotope ratio to detect the accuracy of activity ratio, results are given in Table 3 .

The results of three replicate analyses of uranium isotope ratios in coal, bottom and fly ash samples from coal-fired thermal plants are summarized in Table 4 with the objective of detecting any variability in the presence and potential source of anthropogenic uranium. The ${ }^{235} \mathrm{U} /{ }^{238} \mathrm{U}$ isotope ra-

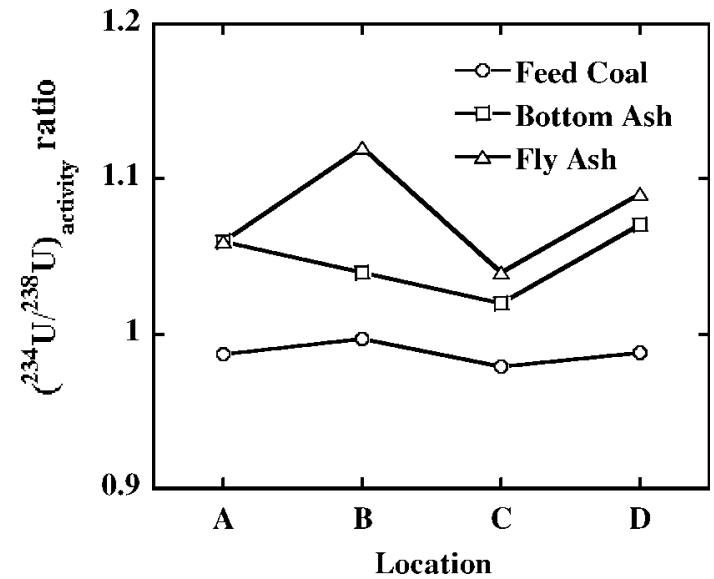

Fig. 3. Activity ratio of feed coal, bottom and fly ash samples.

tios fall in the range of 0.007245 to 0.007259 which are expected for natural uranium and close to the well known "normal terrestrial" ratio of 0.00725 . From replicate runs of each sample, one can confirm that such deviations from natural ratios were readily reproducible at statistical levels predicted by standard measurements.

${ }^{234} \mathrm{U} /{ }^{238} \mathrm{U}$ isotope ratio has been expressed as activity ratio, it varies from the lowest i.e. $0.979 \sim 1.12$, showing an increase in the natural abundance of ${ }^{234} \mathrm{U}$ in the samples. The original ${ }^{235} \mathrm{U} /{ }^{238} \mathrm{U}$ ratio was established in the $r$-process (rapid neutron capture) of nucleosynthesis in a stellar, presolar environment and has then decreased due to alpha decay since that time, leading to the present terrestrial ratio [19]. Although mass spectrometric measurements are calculated on the abundance ratio, the obtained abundance ratios are re-calculated to the radioactivity ratio taking into account the decay constant. Thus, it becomes very easy to discuss the accomplishment of radioactive secular equilibrium when $\left({ }^{234} \mathrm{U} /{ }^{238} \mathrm{U}\right)_{\text {activity }}=$ unity. It can be seen in Fig. 3, some uranium samples appear not to be in radioactive equilibrium. Kigoshi [24] proved that ${ }^{234} \mathrm{Th}$ is ejected into the aqueous phase from the surface of zircon into the coexisting aqueous phase as an effect of recoil energy. As a result, the ${ }^{234} \mathrm{U}$ content in water phase of nature is often too high in comparison with its content in solid silicate phase. It is very likely that the pore water of fly ash contained slight excess of ${ }^{234} \mathrm{U}$. To the contrary, if weathering proceeds to excess, it is probable that the radioactivity ratio in question becomes lower than unity. In case of feed coal samples, all values are less than unity. However, activity ratios were higher in case of fly ash samples followed by bottom ash samples.

Table 4. Isotopic composition of ${ }^{234} \mathrm{U} /{ }^{238} \mathrm{U}$ and ${ }^{235} \mathrm{U} /{ }^{238} \mathrm{U}$ in coal and ash samples.

\begin{tabular}{lcccccc}
\hline Location & \multicolumn{2}{c}{$\mathrm{FC}$} & \multicolumn{2}{c}{$\mathrm{F}$} \\
& ${ }^{234} \mathrm{U} /{ }^{238} \mathrm{U}$ & ${ }^{235} \mathrm{U} /{ }^{238} \mathrm{U}$ & ${ }^{234} \mathrm{U} /{ }^{238} \mathrm{U}$ & ${ }^{235} \mathrm{U} /{ }^{238} \mathrm{U}$ & ${ }^{234} \mathrm{U} /{ }^{238} \mathrm{U}$ & ${ }^{235} \mathrm{U} /{ }^{238} \mathrm{U}$ \\
\hline $\mathrm{A}$ & $0.987 \pm 0.03$ & $0.007248 \pm 11$ & $1.06 \pm 0.02$ & $0.007246 \pm 13$ & $1.06 \pm 0.02$ & $0.007257 \pm 12$ \\
$\mathrm{~B}$ & $0.997 \pm 0.01$ & $0.007254 \pm 13$ & $1.04 \pm 0.03$ & $0.007247 \pm 14$ & $1.12 \pm 0.02$ & $0.007245 \pm 13$ \\
$\mathrm{C}$ & $0.979 \pm 0.02$ & $0.007247 \pm 14$ & $1.02 \pm 0.05$ & $0.007248 \pm 15$ & $1.04 \pm 0.03$ & $0.007252 \pm 12$ \\
$\mathrm{D}$ & $0.988 \pm 0.03$ & $0.007251 \pm 13$ & $1.07 \pm 0.04$ & $0.007249 \pm 16$ & $1.09 \pm 0.04$ & $0.007259 \pm 15$ \\
\hline
\end{tabular}

${ }^{234} \mathrm{U} /{ }^{238} \mathrm{U}$ isotope ratio stands for activity ratio and errors are given as $2 \sigma$ std $\operatorname{dev}$ and ${ }^{235} \mathrm{U} /{ }^{238} \mathrm{U}$ ratio analytical uncertainties refer to the least digit of significant figures. 


\section{Conclusions}

We have measured ${ }^{234} \mathrm{U} /{ }^{238} \mathrm{U}$ and ${ }^{235} \mathrm{U} /{ }^{238} \mathrm{U}$ ratios in coal and fly ash samples to better than $0.2 \%$ at two standard deviation (sd). This method should be applicable to a wide range of environmental and geological problems which are limited by sample size or for which higher precision is required. Results obtained here for uranium activity ratios are preliminary in nature. However, systematic studies are necessary to ascertain the behavior of activity in surrounding area soil samples to study soil water interaction.

Acknowledgment. One of us (SKS) is highly grateful to Professor A. Masuda, University of Tokyo for zircon sample and helpful discussions. V. K. Parami was awarded a fellowship grant under Nuclear Researchers Exchange Program, Ministry of Education, Science and Technology of Japan (NSRA/MEXT) to visit NIRS, Chiba, Japan in co-operation with the Philippine Nuclear Research Institute. The authors express their sincere thanks for the assistance to Mr. S. Canete and Mr. H. Arae.

\section{References}

1. Tadmor, J.: Radioactivity from coal-fired power plants: a review. J. Environ. Radioact. 4, 177 (1986).

2. UNSCEAR: Sources and effects of ionizing radiation. Report to the general assembly, Vol. 1. United Nations, New York (2000).

3. ASTDR: Toxicological profile for uranium, ATSDR report. Agency for Toxic substances and Disease Registry, Atlanta (1999).

4. Rosman, K. J. R., Taylor, P. D. P.: Isotopic composition of the elements 1997 (Technical report). Pure Appl. Chem. 70, 217 (198).

5. Ivanovich, M., Harmon, R. S.: Uranium Series Disequilibrium: Applications to Earth, Marine and Environmental Sciences. $2^{\text {nd }}$ Edn., Clarendon Press, Oxford (1993).

6. Boulyga, S. F., Becker, J. S., Matusevitch, J. L., Dietze, H. J.: Isotope ratio measurements of spent reactor uranium in environmental samples by using inductively coupled plasma mass spectrometry. Int. J. Mass Spectrom. 203, 143 (2000).

7. Jia, G., Belli, M., Sansone, U., Rosamilia, S., Gaudino, S.: Concentration and characteristics of depleted uranium in water, air and biological samples collected in Serbia and Montenegro. Appl. Radiat. Isot. 63, 381 (2005).

8. Chen, J. H., Edwards, R. L., Wasserburg, G. J.: ${ }^{238} \mathrm{U},{ }^{234} \mathrm{U}$ and ${ }^{232} \mathrm{Th}$ in seawater. Earth Planet. Sci. Lett. 65, 241 (1986).

9. Luo, X. Z., Rehkämper, M., Lee, D. C., Halliday, A. N.: High precision ${ }^{230} \mathrm{Th} /{ }^{232} \mathrm{Th}$ and ${ }^{234} \mathrm{U} /{ }^{238} \mathrm{U}$ measurement using energyfiltered ICP magnetic sector multiple collector mass spectrometry. Int. J. Mass Spectrom. Ion Processes 171, 105 (1997).

10. Yokoyama, T., Makishima, A., Nakamura, E.: Precise analysis of ${ }^{234} \mathrm{U} /{ }^{238} \mathrm{U}$ ratio using $\mathrm{UO}_{2}{ }^{+}$ion with thermal ionization mass spectrometry for natural samples. Chem. Geol. 181, 1 (2001).
11. Prohaska, T., Hann, S., Latkoczy, C., Stingeder, G.: Determination of rare earth elements $U$ and $T h$ in environmental samples by inductively coupled plasma double focusing sectorfield mass spectrometry (ICP-SMS). J. Anal. At. Spectrom. 14, 1 (1999).

12. Howe, S. E., Davidson, C. M., McCartney, M.: Determination of uranium concentration and isotopic composition by means of ICP-MS in sequential extracts of sediments from the vicinity of a uranium enrichment plant. J. Anal. At. Spectrom. 17, 497 (2002).

13. Helal, I., Zahran, N. F., Amr, M. A. A., El-Lateef, A., Bashter, I. I., Mohsen, H. T., Abbas, Y.: Ultratrace and isotope ratios analyses of some radionuclides by ICP-MS. Radiochim. Acta 92, 369 (2004).

14. Cohen, A. S., Belshaw, N. S., O'Nions, R. K.: High precision uranium, thorium and radium isotope ratio measurements by high dynamic range thermal ionisation mass spectrometry. Int. J. Mass Spectrom. Ion Processes. 116, 71 (1992).

15. Sahoo, S. K., Yonehara, H., Kurotaki, K., Fujimoto, K., Nakamura, Y.: Precise determination of ${ }^{235} \mathrm{U} /{ }^{238} \mathrm{U}$ isotope ratio in soil samples by using thermal ionisation mass spectrometry. J. Radioanal. Nucl. Chem. 252, 241 (2002).

16. Parrish, R. R., Thirwall, M. F., Pickford, C., Horstwood, M., Gerdes, A., Anderson, J., Coggon, D.: Determination of ${ }^{238} \mathrm{U} /{ }^{235} \mathrm{U}$, ${ }^{238} \mathrm{U} /{ }^{236} \mathrm{U}$ and uranium concentration in urine using SF-ICP-MS and MC-ICP-MS: an interlaboratory comparison. Health Phys. 90, 127 (2006).

17. Yang, Lu: Accurate and precise determination of isotopic ratios by MC-ICP-MS: a review. Mass Spectrom. Rev. 28, 990 (2009).

18. Palacz, Z. A., Freedman, P. A., Walder, A. J.: Thorium isotope ratio measurements at high abundance sensitivity using a VG 54-30, an energy-filtered thermal ionization mass spectrometer. Chem. Geol. 101, 157 (1992).

19. Ritcher, S., Alonso, A., Wellum, R., Taylor, P. D. P.: The isotopic composition of commercially available uranium chemical reagents. J. Anal. At. Spectrom. 14, 889 (1999).

20. Croudace, I., Warwick, P., Taylor, R., Dee, S.: Rapid procedure for plutonium and uranium determination in sols using a borate fusion followed by ion-exchange and extraction chromatography. Anal. Chim. Acta 371, 217 (1998).

21. Godall, P., Lythgoe, C.: Rapid separation of uranium and plutonium by extraction chromatography for determination by thermal ionisation mass spectrometry. Analyst 124, 263 (1999).

22. Sahoo, S. K., Yonehara, H., Kurotaki, K., Shiraishi, K., Ramzaev, V., Barkovski, A.: Determination of rare earth elements, thorium and uranium by ICPMS and Sr isotopes by TIMS in soil samples of Bryansk region contaminated due to Chernobyl accident. J. Radioanal. Nucl. Chem. 247, 341 (2001).

23. Hassan, N. M., Ishikawa, T., Hosoda, M., Sorimachi, A., Tokonami, S., Fukushi, M., Sahoo, S. K.: Assessment of the natural radioactivity using two techniques for the measurement of radionuclide concentration in building materials used in Japan. J. Radioanal. Nucl. Chem. 283, 15 (2010).

24. Kigoshi, K.: Alpha-recoil thorium-234: dissolution into water and the uranium-234/uranium-238 disequilibrium in nature. Science 173, 47 (1971). 